\title{
Plasma Lipocalin-2 and Adiponectin are Affected by Obesity Rather Than Type 2 Diabetes Mellitus per se
}

\author{
Boshra Al-Absi \\ Molham AL-Habori (D) \\ Riyadh Saif-Ali
}

Department of Biochemistry and Molecular Biology, Faculty of Medicine and Health Sciences, University of Sana 'a, Sana'a, Yemen
Correspondence: Molham AL-Habori Email malhabori@hotmail.com
Purpose: Changes in plasma adipocytokines and inflammatory markers in type 2 DM remain controversial as to whether they are due to obesity or directly associated with the diabetic state. Our objective was to study the effect of obesity and diabetes on plasma lipocalin-2 (LCN2), adiponectin, and interleukin-1 $\beta$ (IL-1 $\beta$ ) by comparing their levels in non-diabetic obese subjects and non-obese type 2 DM patients, as well as determining the association of these adipocytokines with metabolic syndrome factors and diabetic parameters.

Patients and Methods: In this study, 85 Yemeni male volunteers aged 30-60 years old were enrolled, 25 of whom were healthy subjects with BMI $<25 \mathrm{~kg} / \mathrm{m}^{2}$ served as control; 30 non-diabetic obese subjects (BMI $\geq 30 \mathrm{~kg} / \mathrm{m}^{2}$ and $\left.\mathrm{FBG}<6.1 \mathrm{mmol} / \mathrm{l}\right)$; and 30 non-obese type 2 DM patients (BMI $<25 \mathrm{~kg} / \mathrm{m}^{2}$ and $\left.\mathrm{FBG}>7 \mathrm{mmol} / \mathrm{l}\right)$.

Results: Lipocalin-2 and adiponectin were significantly $(\mathrm{p}=0.043$ and $\mathrm{p}=0.034)$ lower in non-diabetic obese subjects by $16.2 \%$ and $29.7 \%$ with respect to control group, with no effect in the non-obese type $2 \mathrm{DM}$ patients. Moreover, LCN2 was significantly $(\mathrm{p}=0.04)$ lower in the non-diabetic obese subjects by $15.8 \%$ as compared with the non-obese type $2 \mathrm{DM}$ patients, with no significant difference in adiponectin levels. In contrast, serum IL-1 $\beta$ was significantly $(\mathrm{p}=0.001$ and $\mathrm{p}=0.003)$ higher in both non-diabetic obese subjects and the non-obese type $2 \mathrm{DM}$ patients by $76.5 \%$ and $67.7 \%$ as compared to control group. The significant decrease in both LCN2 and adiponectin and the significant increase in IL-1 $\beta$ in the non-diabetic obese subjects disappeared upon adjustment for waist circumference (WC). In contrast, the significant increase in IL-1 $\beta$ in the non-obese Type 2 DM patients was not affected upon adjustment for WC.

Conclusion: Plasma LCN2 and adiponectin were not affected by diabetes per se, suggesting that the observed changes in LCN2 and adiponectin in type 2 DM may be due to obesity rather than the diabetic state, whereas IL-1 $\beta$ levels were affected by both obesity and diabetes.

Keywords: lipocalin-2, adiponectin, interleukin-1 $\beta$, obesity, type 2 DM

\section{Introduction}

Lipocalin-2 (LCN2), also known as neutrophil gelatinase associated lipocalin and siderocalin, is a $25-\mathrm{kDa}$ glycoprotein originally purified from human neutrophils. It belongs to the lipocalin superfamily, which can bind and transport small lipophilic molecules. ${ }^{1,2}$ Lipocalin-2 is expressed in many tissues and cell types, including adipocytes, $^{3,4}$ hepatocytes, ${ }^{5,6}$ renal tubular cells, ${ }^{7-9}$ and bone osteoblasts. ${ }^{10,11}$ Expression and secretion of LCN2 increase after conversion of preadipocytes to mature adipocytes. ${ }^{12}$ Lipocalin-2 expression is induced by many pro- and antiinflammatory cytokines such as lipopolysaccharide (LPS), tumor necrosis factor- $\alpha$ 
(TNF- $\alpha$ ), and several interleukins (IL-1 $\beta$, IL-6 and IL-17) in a variety of cell types. ${ }^{13}$ Lipocalin-2 was initially discovered to play an important role in the innate immune response to bacterial infection, as well as in the regulation of cell proliferation and apoptosis. ${ }^{1,2,14,15}$

Lipocalin-2 is implicated in diseases associated with inflammation including acute and chronic kidney injury, ${ }^{9}$ acute liver injury, ${ }^{6}$ and pancreatic adenocarcinoma. ${ }^{16}$ Lipocalin-2 is also associated with bone metabolism, suggesting that LCN2 exerted both a negative effect on bone formation and a positive effect on bone resorption. ${ }^{10,17}$ Moreover, osteoblast-derived LCN2 has been shown to cross the blood-brain barrier and suppress appetite, thus decreasing body weight and fat mass and improving glucose tolerance and insulin sensitivity. ${ }^{11}$ Lipocalin-2, as an adipose tissue-derived cytokine, has been found to potentially be involved in obesity-related abnormalities and cardiovascular disease (CVD) through the regulation of inflammatory responses. ${ }^{13,18-20}$ In addition, LCN2 plays a crucial role in vascular remodeling and plaque instability ${ }^{13}$ and has been suggested to be an early biomarker for predicting CVD events than the traditional inflammatory marker C-reactive protein (CRP). ${ }^{20}$ Accumulating evidence has also linked LCN2 to insulin resistance and obesity-related metabolic diseases. ${ }^{3,12,21}$

Adiponectin is also an adipocyte-derived cytokine that is closely associated with obesity, altered body fat distribution, insulin resistance, and atherosclerosis. ${ }^{22}$ Evidence from animal and human studies demonstrates that adiponectin plays an important role in the regulation of glucose and lipid metabolism, maintaining metabolic homeostasis and is closely involved in the development of Type 2 DM. ${ }^{23-25}$ Adiponectin has been reported to have antidiabetic, anti-atherogenic, and anti-inflammatory properties. ${ }^{26}$ It promotes insulin sensitization by reducing hepatic glucose production and increasing insulin sensitivity in the liver. A number of prospective studies demonstrated that high levels of circulating adiponectin are associated with low risk of Type 2 DM even after adjustment for multiple factors that could confound this relationship. ${ }^{27,28}$

Increasing evidence suggests that serum LCN2 and adiponectin levels may be beneficial biomarkers for evaluating outcomes in various clinical settings of obesity-related abnormalities. However, it remains controversial whether the observed changes in plasma adipocytokines and inflammatory markers in Type $2 \mathrm{DM}$ patients are due to excess adipose tissue mass or directly associated with the diabetic state. ${ }^{29}$ The present study was aimed at examining the effect of obesity and diabetes on plasma adipocytokines (lipocalin-2 and adiponectin) and the pro-inflammatory marker interleukin-1 $\beta$ (IL-1 $\beta$ ) by comparing their levels in nondiabetic obese subjects and non-obese Type 2 DM patients versus non-obese, normoglycemic controls; as well as assessing the association of adipocytokines and inflammatory markers with metabolic syndrome and diabetes-related quantitative traits.

\section{Patients and Methods Study Design, Subjects and Data Collection}

This case-control study was performed on 85 Yemeni male subjects aged 30-60 years, 25 healthy non-obese, normoglycemic subjects with BMI $<25 \mathrm{~kg} / \mathrm{m}^{2}$ served as controls, 30 obese non-diabetic subjects with BMI $\geq 30 \mathrm{~kg} / \mathrm{m}^{2}$ and $\mathrm{FBG}<6.1 \mathrm{mmol} / \mathrm{l}$, and 30 non-obese Type $2 \mathrm{DM}$ patients with $\mathrm{BMI}<25 \mathrm{~kg} / \mathrm{m}^{2}$ and $\mathrm{FBG}>7 \mathrm{mmol} / \mathrm{l}$ recruited during their routine visits to the Endocrine and Diabetic Clinic of Al-Thawra Hospital, Sana'a. Obese Type 2 DM patients were excluded in order to examine the role of diabetes per se. All the enrolled Type 2 DM patients were diagnosed more than 2 months and less than 5 years, controlled by diet or by oral anti-diabetic agents for at least $\geq 2$ months after diagnosis. Subjects with acute or chronic infections, severe medical conditions (malignancy, renal failure, liver cirrhosis, connective tissue disease, and chronic congestive heart failure) were excluded from the study. The study protocol was approved by the Institutional Review Board (IRB) of the Faculty of Medicine and Health Sciences, Sana'a University. Informed consent form was obtained from all individuals after explaining the purpose and nature of the study.

Standard physical examinations including clinical variables were assessed as previously described. ${ }^{30}$ The subjects' height and weight were measured and BMI, defined as weight $(\mathrm{kg}) /$ height squared $\left(\mathrm{m}^{2}\right)$, was calculated. Waist circumference (WC) was measured halfway between the lower rib margin and the anterior superior iliac spine. Blood pressure (BP) measurements were taken from each patient's right arm in the seated position by using an Omron IntelliSense automatic blood pressure monitor after 10 min of rest. Two to three successive BP readings were obtained at 5 minute intervals and averaged. A fasting venous blood $(5 \mathrm{~mL})$ was collected from each patient after an overnight fast of more than 10 hours and 
divided into two vacuumed tubes; $4 \mathrm{~mL}$ into plain tubes for biochemical analysis and $1 \mathrm{~mL}$ into sodium fluoride (for glucose measurement). The serum from each sample was separated within 30 minutes and aliquoted into four Eppendorf tubes and immediately stored at $-60^{\circ} \mathrm{C}$ for biochemical analysis.

\section{Biochemical Analysis}

Fasting blood glucose (FBG), triglyceride (TG), total cholesterol, HDL-cholesterol (HDL-c), and LDL-cholesterol (LDL-c) were measured on an automated analyzer, the Cobas c501 (Roche Diagnostic, Germany), using the respective Roche Diagnostic kits (Roche Diagnostic, Germany). Insulin was measured by an electrochemiluminescence immunoassay (ECL) on an Elecsys autoanalyzer (Roche Diagnostic, Germany). Insulin resistance (HOMAIR) and $\beta$-cell function (HOMA- $\beta$ ) were calculated using the Homeostasis Model Assessment (HOMA2) calculator v2.2 which is available from the Oxford Centre for Diabetes, Endocrinology, and Metabolism. Serum LCN2, adiponectin and IL-1 $\beta$ were measured by enzyme-linked immunoassay (ELISA) kits (R\&D Systems, USA).

\section{Statistical Analysis}

The results were analyzed by the Social Package of Social Sciences (SPSS) version 11.5 (SPSS Inc, Chicago, IL, USA). Data normality was verified using Kolmogorov-Smirnov test, and the skewed distributed data were square root transformed and were subsequently transformed back and reported as geometric means and $95 \%$ confidence intervals. ANOVA test was used to describe the mean differences among groups of study. General linear model, univariate analyses (ANCOVA) adjusted for age was used to assess the differences of LCN2, adiponectin, leptin and IL-1 $\beta$ between non-diabetic obese, non-obese Type 2 DM and normal subjects. The association of LCN2, adiponectin and IL-1 $\beta$ with metabolic syndrome and diabetes-related qualitative traits (dependent variables) were analyzed by simple linear regression adjusted for age in a combined group: normal and obese non-diabetic subjects. The interrelationship between LCN2, adiponectin and IL-1 $\beta$ in non-diabetic subjects was evaluated by linear regression controlled for age. The significant differences were indicated if $\mathrm{p}$-value was $<0.05$.

\section{Results}

The demographic and biochemical parameters of the study subjects are shown in Table 1. The LCN2, adiponectin and IL-
$1 \beta$ assessed by general linear model (univariate) are shown in Table 2. Serum levels of LCN2 and adiponectin were significantly ( $p=0.043, p=0.034$ ) lower in non-diabetic obese subjects by $16.2 \%$ and $29.7 \%$, respectively, as compared with control group; with no significant differences in LCN2 and adiponectin between non-obese Type 2 DM patients and controls. On comparing the non-diabetic obese subjects with the non-obese Type $2 \mathrm{DM}$ patients, LCN2 was significantly ( $\mathrm{p}=$ 0.04 ) lower in the non-diabetic obese subjects by $15.8 \%$; whereas adiponectin was non-significantly lower in the nondiabetic obese subjects by $22.6 \%$. In contrast, serum IL- $1 \beta$ was significantly $(\mathrm{p}=0.001, \mathrm{p}=0.003$ ) higher in both nondiabetic obese subjects and non-obese Type 2 DM patients by $76.5 \%$ and $67.7 \%$ with respect to the control group, with no significant difference in IL-1 $\beta$ between non-diabetic obese subjects and non-obese Type $2 \mathrm{DM}$ patients.

The observed significant decrease in both LCN2 and adiponectin as well as the significant increase in IL- $1 \beta$ in the non-diabetic obese subjects disappeared upon adjustment for WC (Table 2). In contrast, the observed significant increase in IL-1 $\beta$ in the non-obese Type 2 DM patients was not affected upon adjustment for WC.

The association of the inflammatory-related variables (LCN2, adiponectin and IL-I $\beta$ ) with metabolic syndrome and diabetes-related qualitative traits was evaluated in the non-diabetic subjects (Table 3). Serum LCN2 was significantly associated with decreased BMI, WC, HOMA-IR and IL-I $\beta(\mathrm{r}=-0.293, \mathrm{p}=0.03 ; \mathrm{r}=-0.346, \mathrm{p}=0.01$; $\mathrm{r}=-0.265, \mathrm{p}=0.049 ; \mathrm{r}=-0.321, \mathrm{p}=0.017)$. Along the same line, adiponectin was significantly associated with decreased BMI, WC, systolic blood pressure (SBP), diastolic blood pressure (DBP), TG, insulin, HOMA-IR, and HOMA- $\beta$ ( $\mathrm{r}=-0.347, \mathrm{p}=0.009 ; \mathrm{r}=-0.335, \mathrm{p}=0.012$; $\mathrm{r}=-0.270, \mathrm{p}=0.047 ; \mathrm{r}=-0.315, \mathrm{p}=0.019 ; \mathrm{r}=-0.291$, $\mathrm{p}=0.031 ; \mathrm{r}=-0.427, \mathrm{p}=0.001 ; \mathrm{r}=-0.457, \mathrm{p}=0.001 ; \mathrm{r}=$ - 0.356, $\mathrm{p}=0.008)$. In contrast, IL-1 $\beta$ was significantly associated with increased BMI, WC, SBP and FBG ( $\mathrm{r}=$ $0.487, \mathrm{p}=0.0002 ; \mathrm{r}=0.435, \mathrm{p}=0.001 ; \mathrm{r}=0.305, \mathrm{p}=$ $0.023 ; \mathrm{r}=0.321, \mathrm{p}=0.017$ ); and border-line significant with increased HOMA-IR $(r=0.26, p=0.055)$.

\section{Discussion}

The results presented in this study show plasma LCN2 and adiponectin to be significantly lower in non-diabetic obese individuals as compared to both control and non-obese Type 2 DM patients, with no difference in LCN2 and adiponectin between non-obese Type 2 DM and control group; thus suggesting that the inconsistent reported 


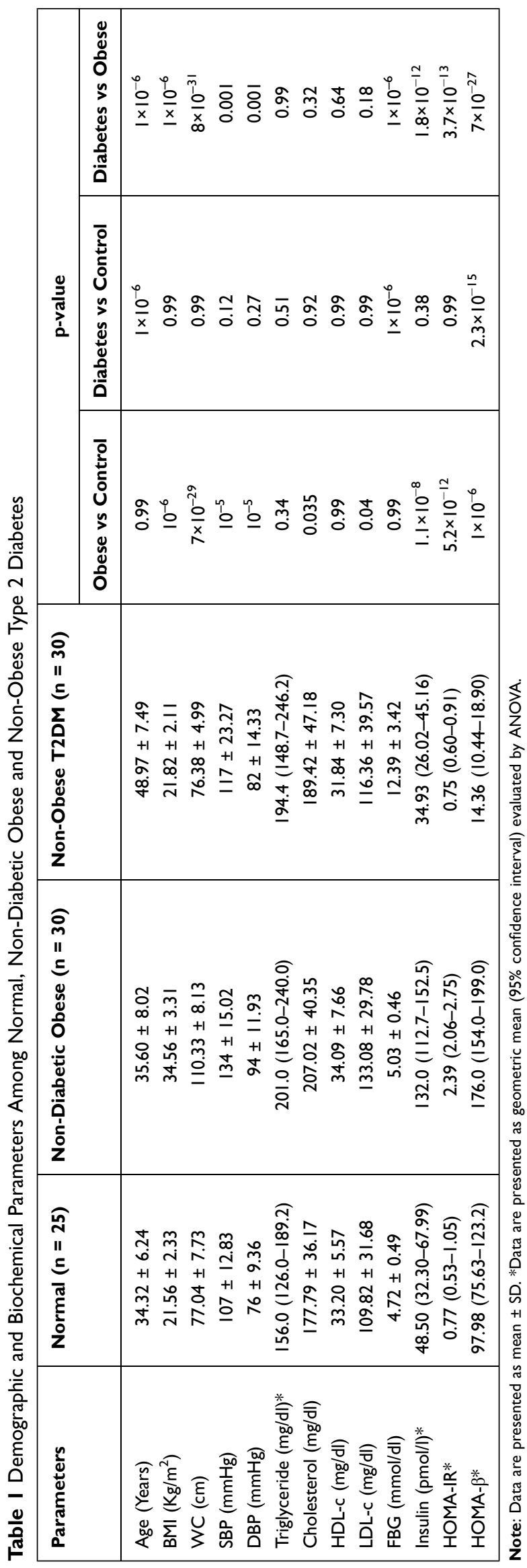

changes in plasma LCN $2^{21,31-33}$ and that of adiponectin $^{29,32,34-36}$ in Type 2 DM patients may be due to excess adipose tissue mass/obesity rather than diabetes per se. In general, most of the Type 2 DM patients included in those studies were obese. Moreover, our results show that upon adjustment for WC the significant decrease of LCN2 and adiponectin in the non-diabetic obese subjects disappeared. In contrast, plasma IL-1 $\beta$ was increased in both non-diabetic obese subjects and nonobese Type $2 \mathrm{DM}$ patients; and upon adjustments for $\mathrm{WC}$, the significant increase of IL-1 $\beta$ in non-diabetic obese subjects disappeared whereas that in the non-obese Type 2 DM patients was not affected suggesting that unlike LCN2 and adiponectin, IL- $1 \beta$ is affected by Type 2 DM.

The observed lack of effect on LCN2 in the non-obese Type 2 DM with respect to the control group is in disagreement with what has been reported by different research groups, $3,21,31,33,37,38$ demonstrating an increase of LCN2 in obese subjects and Type 2 DM patients than those in lean and non-Type 2 DM subjects. ${ }^{21}$ The latter study also showed the significant increase in LCN2 in Type 2 DM patients disappeared upon adjustment for BMI. Moreover, analysis of the circulating levels of LCN2 in a large Chinese population showed a nonsignificant increase of LCN2 levels in pre-diabetic patients and that LCN2 was independently associated with impaired glucose regulation, thus suggesting that the LCN2 changes depend on both the grade of tissue damage caused by diabetes and the duration of diabetes. ${ }^{31}$

Other studies, however, showed a significant decrease of LCN2 levels in Type 2 DM patients in comparison with healthy subjects ${ }^{32,39}$ and inferred that the decrease in LCN2 levels may not be a direct consequence of either increased BMI or impaired glucose metabolism, but may depend on the duration of the diabetes, the level of inflammation and presence of cardiometabolic changes. Lipocalin-2 was also suggested to be involved in insulin resistance and cardiometabolic alterations through an undefined mechanism produced by the inflammation process $^{32}$ and that the interrelationship with the other cytokines in Type $2 \mathrm{DM}$ patients may be prompting the reduction in plasma LCN2. ${ }^{31}$ Lipocalin-2 deficiency has been shown to protect mice from developing obesity-induced insulin resistance largely by modulating TNF- $\alpha$ levels in adipose tissue. ${ }^{12}$

The decreased LCN2 in our non-diabetic obese subjects may be attributed to the over activation of inflammation, since obesity is a low-grade systemic inflammatory condition. $^{40}$ Thus, LCN2 may principally act as a negative 


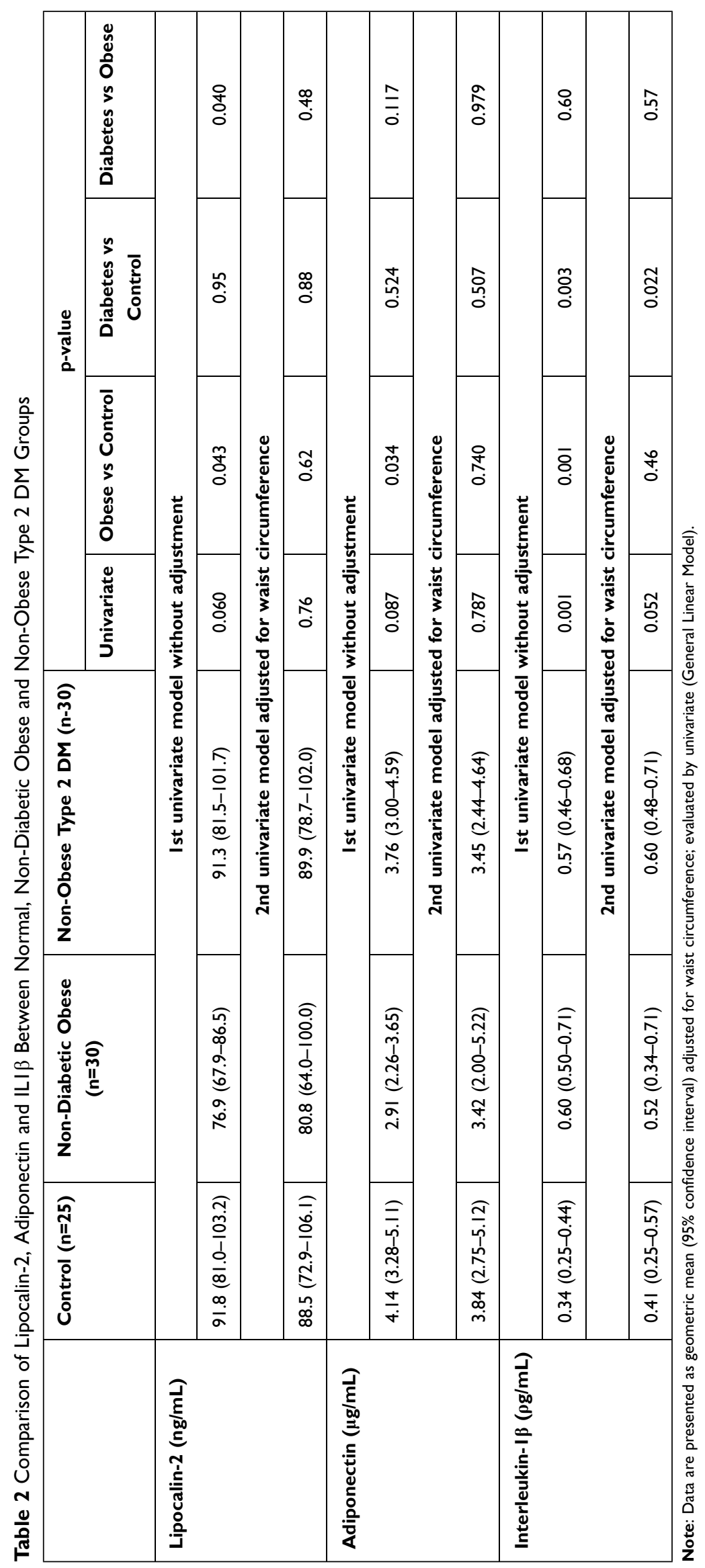


Table 3 Association of Lipocalin-2, Adiponectin and Interleukin-I $\beta$ with Metabolic Syndrome Factors and Diabetic Parameters Among Non-Diabetic Subjects

\begin{tabular}{|l|c|c|c|}
\hline Parameters & Lipocalin-2 & Adiponectin & Interleukin-I $\beta$ \\
\hline BMI & $-0.293(0.03)$ & $-0.347(0.009)$ & $0.487(0.0002)$ \\
Waist Circumference & $-0.346(0.010)$ & $-0.335(0.012)$ & $0.435(0.001)$ \\
SBP & $-0.233(0.087)$ & $-0.270(0.047)$ & $0.305(0.023)$ \\
DBP & $-0.207(0.129)$ & $-0.315(0.019)$ & $0.246(0.070)$ \\
Triglyceride & $0.032(0.819)$ & $-0.291(0.031)$ & $0.007(0.962)$ \\
HDL-C & $-0.003(0.980)$ & $0.166(0.277)$ & $0.171(0.213)$ \\
LDL-c & $-0.161(0.239)$ & $0.120(0.381)$ & $0.205(0.134)$ \\
FBG & $-0.119(0.386)$ & $-0.182(0.184)$ & $0.321(0.017)$ \\
Insulin & $-0.209(0.126)$ & $-0.427(0.001)$ & $0.223(0.101)$ \\
HOMA-IR & $-0.265(0.049)$ & $-0.457(0.0005)$ & $0.260(0.055)$ \\
HOMA- $\beta$ & $-0.141(0.305)$ & $-0.356(0.008)$ & $0.124(0.368)$ \\
Lipocalin-2 & - & $0.068(0.62)$ & $-0.321(0.017)$ \\
Adiponectin & - & $-0.034(0.804)$ \\
\hline
\end{tabular}

Note: Data presented represent $b$ values ( $p$ values) assessed by linear regression adjusted for age.

regulator of inflammatory activity and inflammationmediated adipocyte dysfunction. The anti-inflammatory function of LCN2 is suggested to be associated with its modulation of the peroxisomal proliferator-activated receptors- $\gamma(\operatorname{PPAR} \gamma)$ activity via direct or indirect mechan-

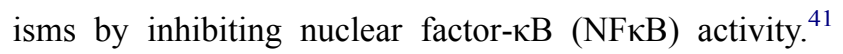
Lipocalin-2 was also demonstrated to induce PPAR $\gamma$ expression in the absence of insulin in adipocytes; with the effect of LCN2 on insulin action being relatively small. $^{42}$ In addition, LCN2 null mice (lacking LCN2) show improved glucose tolerance and insulin sensitivity. ${ }^{43}$

Our results showed that serum LCN2 was significantly associated with decreased BMI, WC and HOMA-IR, which is in contrast to that reported by earlier studies whereby LCN2 levels were positively correlated with adiposity, hyperglycemia, and insulin resistance index; $;^{3,21,37,44,45}$ with WC being more closely related to LCN2 than BMI. ${ }^{34,48}$ A number of studies also suggested that LCN2 might be an indicator for $\beta$-cell function and insulin resistance in Type 2 DM. ${ }^{31,38}$ Since chronic inflammation is likely to contribute to the pathogenesis of Type 2 DM, we also examined the association between LCN2 and IL-1 $\beta$, a pro-inflammatory marker that acts as a key promoter of systemic and tissue inflammation in Type $2 \mathrm{DM} ;{ }^{46}$ and found that LCN2 was inversely correlated with IL-1 $\beta$ levels suggesting that LCN2 may be an important link between adiposity, inflammation and Type 2 DM. $^{47,48}$

The adiponectin results in this study further confirmed our previous study showing adiponectin not to be affected by diabetes per $\mathrm{se}^{30}$ and is in accordance with several studies. ${ }^{23,49-51}$ A recent study compared diabetic females with concomitant obesity to those with severe obesity and showed that plasma adiponectin level was not affected by diabetes per se. ${ }^{23}$ Moreover, an earlier study also compared adiponectin levels between obese and non-obese Type 2 DM patients and demonstrated that the observed changes in obese Type 2 DM patients as compared to nonobese Type $2 \mathrm{DM}$ are attributed to the greater adipose tissue mass, and not to the diabetic state. ${ }^{49}$ A more recent population-based cohort study reported that adiponectin levels differed based on the degree of obesity in newly diagnosed Type 2 DM patients by comparing obese Type 2 DM with non-obese Type 2 DM. ${ }^{52}$ However, other studies showed adiponectin to depend on concomitant obesity and Type 2 DM duration. ${ }^{53,54}$

On the other hand, our results are in disagreement with a number of studies ${ }^{29,32,34-36,55-57}$ reporting adiponectin to be lower in Type 2 DM patients than in subjects with normal glucose tolerance. Adiponectin levels were also reported to be significantly different according to the presence of microangiopathy, whereby adiponectin was significantly higher in Type 2 DM patients with neuropathy and retinopathy, but significantly lower in those with nephropathy. ${ }^{55}$ A meta-analysis of prospective studies assessed the association of adiponectin with risk of Type 2 DM showed considerable heterogeneity between studies and suggested that more research is required to clarify this relationship. ${ }^{58}$

Our results also showed adiponectin to be inversely correlated with metabolic syndrome factors (BMI, WC and TG) and diabetic parameters (insulin, HOMA-IR and 
HOMA- $\beta$ ), which is in agreement with previous studies. $^{30,56,57,59}$ Low adiponectin level has been suggested that it can be used to predict both future abdominal visceral fat accumulation and increased insulin resistance. ${ }^{60,61}$ Moreover, an earlier study demonstrated serum adiponectin levels to be inversely correlated with the severity of insulin resistance in Type 2 DM patients. ${ }^{62}$ However, the relationship between adiponectin and insulin sensitivity is influenced by ethnic differences and was found to vary between different populations, ${ }^{63}$ which may have an important role to play in the susceptibility of certain populations to obesity and associated CVD morbidities. ${ }^{64}$ Interestingly, single-nucleotide polymorphisms (SNPs) of the adiponectin promoter region were demonstrated to be significantly associated with lower insulin sensitivity in overweight/obese Italian children. ${ }^{65}$ An earlier study also showed the inverse association between serum adiponectin and insulin resistance to become weaker upon adjustment for metabolic syndrome components, suggesting that these associations are not entirely confounded by metabolic syndrome. ${ }^{56}$ The same study also showed that the reduced demand for insulin section is largely driven by improved insulin sensitivity arising from increased levels of adiponectin; ${ }^{56}$ thus suggesting that the higher levels of insulin in insulin-resistant subjects may down-regulate the adiponectin levels. ${ }^{66}$ The inverse association between adiponectin and insulin resistance in our results and others ${ }^{30,59}$ may be mediated not only by insulin but also by inflammatory cytokines. ${ }^{67}$

Unlike that of LCN2 and adiponectin, serum IL-1 $\beta$ levels were higher in both non-diabetic obese individuals and non-obese Type 2 DM patients, which is in agreement with several studies. ${ }^{57,68-70}$ Furthermore, the significant increase of serum IL-1 $\beta$ with obesity may result from increased expression of both IL-1 $\beta$ and its receptor in visceral adipose tissue of obese subjects. ${ }^{71}$ Interleukin- $1 \beta$ was suggested to play an important role in obesityassociated inflammation and insulin resistance and may represent a therapeutic target to reverse the unfavorable metabolic consequences of obesity. ${ }^{72,73}$ The raised IL-1 $\beta$ levels in obese individuals and Type 2 DM patients suggest that IL-1 $\beta$ might play a key role in the modulation of $\beta$-cell function and contribute to the pathogenesis of Type 2 DM. $^{46,74}$ Other studies, however, have reported that serum IL-1 $\beta$ levels are not different between subjects with normal glucose tolerance and those with Type 2 DM. $^{75,76}$ These conflicting results suggest that serum IL$1 \beta$ levels in Type 2 DM patients may have been influenced by selecting patients who use anti-diabetic drugs or have progressing diabetic complications. ${ }^{77}$

The present study showed that IL- $1 \beta$ was significantly associated with increased BMI, WC, SBP and FBG. A recent study, although showed no correlation between IL-1 $\beta$ and obesity represented by BMI, however they could not conclude that IL-1 $\beta$ was not correlated with the WC. ${ }^{76}$ The significant increase of IL-1 $\beta$ levels in our non-obese Type $2 \mathrm{DM}$, and the border-line significant positive correlation between IL-1 $\beta$ and HOMA-IR suggest that chronic inflammation may play a role in the development of insulin resistance and Type $2 \mathrm{DM}^{78}$ Increasing evidence suggests that IL- $1 \beta$ is involved in the translation of obesity-associated inflammation into insulin resistance in rodent models. ${ }^{72,73}$ Our results also showed the significant increase in IL-1 $\beta$ in the non-diabetic obese subjects disappeared upon adjustment for $\mathrm{WC}$; whereas the significant increase in IL-1 $\beta$ in the non-obese Type 2 DM patients did not disappear suggesting that unlike LCN2 and adiponectin, IL-1 $\beta$ is affected by Type 2 DM.

The limitations of the present study include: First, the study is hospital-based and all subjects were male; therefore, the findings may not be applicable to the overall population, particularly in view of gender differences in LCN2 and adiponectin plasma levels. Second, the study sample consists mainly of Yemenis and hence the results cannot be generalized to other ethnicities. Third, the sample size was small, limiting its statistical power for detecting associations. Fourth, the $\beta$-cell function was evaluated using the homeostasis model (HOMA- $\beta$ ) which reflects $\beta$ cell activity (ie, insulin secretion) rather than its health or pathological condition. Nevertheless, this study represents an examination of relationships between plasma adipocytokine profile and inflammatory markers in Yemeni nonobese Type 2 DM patients.

\section{Conclusion}

In conclusion, plasma LCN2 and adiponectin were not affected by diabetes per se, suggesting that the reported changes in plasma LCN2 and adiponectin in Type 2 DM may be due to obesity. Moreover, LCN2 and adiponectin exhibited analogous correlations with obesity, and insulin resistance. The significant increment of IL-1 $\beta$ in non-obese Type 2 DM patients, and its border-line significant positive correlation with HOMA-IR suggest that chronic inflammation may play a role in the development of insulin resistance and Type 2DM. In addition, the inverse association between LCN2 and IL-1 $\beta$ infers that LCN2 may be an 
important link between adiposity, inflammation and Type 2 DM. Therefore, adipocytokines together with proinflammatory markers may possibly modulate the pathogenesis of obesity and Type $2 \mathrm{DM}$ and the balances of different pro- and anti-inflammatory cytokines as well as their differing interrelationships need to be investigated to understand the pathogenesis of obesity and Type 2 DM.

\section{Abbreviations}

BMI, Body mass index; BP, Blood pressure; CVD, Cardiovascular disease; CRP, C-reactive protein; DBP, Diastolic blood pressure; ECL, Electrochemiluminescence immunoassay; ELISA, Enzyme linked immunoassay; FBG, Fasting blood glucose; HbA1c, Glycated hemoglobin; HDL-c, High density lipoprotein cholesterol; HOMA, Homeostasis model assessment; HOMA-IR, Insulin resistance; HOMA- $\beta$, $\beta$-cell function; IL-1 $\beta$, Interleukin-1 $\beta$; LCN2, Lipocalin-2; LDL-c, Low density lipoprotein cho-

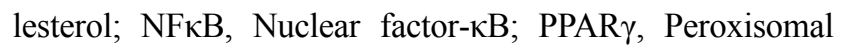
proliferator-activated receptors- $\gamma$; SD, Standard deviation; SPSS, Statistical Package for Social Sciences; SBP, Systolic blood pressure; TG, Triglycerides; TNF- $\alpha$, Tumor necrosis factor- $\alpha$; WC, Waist circumference.

\section{Data Sharing Statement}

The data set generated and/or analyzed during this study are included in this submitted manuscript and is available from the corresponding author on reasonable request.

\section{Ethical Approval}

The study protocol was approved by the Institutional Ethical Committee, Faculty of Medicine and Health Sciences, Sana'a University. The study was in compliance with the Declaration of Helsinki for clinical research. All the recruited participants provided written informed consent before participating in the study.

\section{Acknowledgments}

The authors thank all the study participants.

\section{Disclosure}

The authors report no conflicts of interest in this work.

\section{References}

1. Flo TH, Smith KD, Sato S, et al. Lipocalin 2 mediates an innate immune response to bacterial infection by sequestrating iron. Nature. 2004;432:917-921. doi:10.1038/nature03104
2. Devireddy LR, Gazin C, Zhu X, Green MR. A cell surface receptor for lipocalin $24 \mathrm{p} 3$ selectively mediates apoptosis and iron uptake. Cell. 2005;123:1293-1305. doi:10.1016/j.cell.2005.10.027

3. Yan QW, Yang Q, Mody N, et al. The adipokine lipocalin-2 is regulated by obesity and promotes insulin resistance. Diabetes. 2007;56:2533-2540. doi:10.2337/db07-0007

4. Catalan V, Gomez-Ambrosi J, Rodriguez A, et al. Increased adipose tissue expression of lipocalin-2 in obesity is related to inflammation and matrix metalloproteinase-2 and metalloproteinase-9 activities in humans. $J$ Mol Med. 2009;87:803-813. doi:10.1007/s00109-009-0486-8

5. Xu MJ, Feng D, Wu H, et al. Liver is the major source of elevated serum lipocalin-2 levels after bacterial infection or partial hepatectomy: a critical role for IL-6/STAT3. Hepatology. 2015;61:692-702. doi: $10.1002 /$ hep. 27447

6. Borkham-Kamphorst E, van de Leur E, Zimmermann HW, et al. Protective effects of lipocalin-2 (LCN2) in acute liver injury suggest a novel function in liver homeostasis. Biochim Biophys Acta. 2013;1832:660-673. doi:10.1016/j.bbadis.2013.01.014

7. Devarajan P. Neutrophil gelatinase-associated lipocalin: an emerging troponin for kidney injury. Nephrol Dial Transplant. 2008;23:3737-3743. doi:10.1093/ndt/gfn531

8. Nickolas TL, Forster CS, Sise ME, et al. NGAL (Lcn2) monomer is associated with tubulointerstitial damage in chronic kidney disease. Kidney Int. 2012;82:718-722. doi:10.1038/ki.2012.195

9. Castillo-Rodriguez E, Fernandez-Prado R, Martin-Cleary C, et al. Kidney injury marker 1 and neutrophil gelatinase-associated lipocalin in chronic kidney disease. Nephron. 2017;136(4):263-267. doi:10.1159/000447649

10. Costa D, Lazzarini E, Canciani B, et al. Altered bone development and turnover in transgenic mice over-expressing lipocalin-2 in bone. J Cell Physiol. 2013;228(11):2210-2221. doi:10.1002/jcp.24391

11. Mosialou I, Shikhel S, Liu JM, et al. MC4R-dependent suppression of appetite by bone-derived lipocalin-2. Nature. 2017;543:385-390. doi:10.1038/nature21697

12. Law IK, Xu A, Lam KS, et al. Lipocalin-2 deficiency attenuates insulin resistance associated with aging and obesity. Diabetes. 2010;59:872-882. doi:10.2337/db09-1541

13. Oberoi R, Bogalle EP, Matthes LA, et al. Lipocalin (LCN) 2 mediates pro-atherosclerotic processes and is elevated in patients with coronary artery disease. PLoS One. 2015;10:e0137924. doi:10.1371/journal.pone. 0137924

14. Liu Z, Petersen R, Devireddy L. Impaired neutrophil function in $24 \mathrm{p} 3$ null mice contributes to enhanced susceptibility to bacterial infections. J Immunol. 2013;190:4692-4706. doi:10.4049/jimmunol.1202411

15. Venge P, Douhan-Håkansson L, Garwicz D, Peterson C, Xu S, Pauksen K. Human neutrophil lipocalin as a superior diagnostic means to distinguish between acute bacterial and viral infections. Clin Vaccine Immunol. 2015;22:1025-1032. doi:10.1128/CVI.00347-15

16. Gomez-Chou SB, Swidnicka-Siergiejko AK, Badi N, et al. Lipocalin2 promotes pancreatic ductal adenocarcinoma by regulating inflammation in the tumor microenvironment. Cancer Res. 2017;77 (10):2647-2660. doi:10.1158/0008-5472.CAN-16-1986

17. Rucci N, Capulli M, Piperni SG, et al. Lipocalin-2: a new mechanoresponding gene regulating bone homeostasis. J Bone Miner Res. 2015;30(2):357-368. doi:10.1002/jbmr.2341

18. Eilenberg W, Stojkovic S, Piechota-Polanczyk A, et al. Neutrophil gelatinase-associated lipocalin (NGAL) is associated with symptomatic carotid atherosclerosis and drives pro-inflammatory state in vitro. Eur J Vasc Endovasc Surg. 2016;51(5):623-631. doi:10.1016/ j.ejvs.2016.01.009

19. Ni J, Ma X, Zhou M, et al. Serum lipocalin-2 levels positively correlate with coronary artery disease and metabolic syndrome. Cardiovasc Diabetol. 2013;12:176. doi:10.1186/1475-2840-12-176

20. Wu G, Li H, Fang Q, et al. Elevated circulating lipocalin-2 levels independently predict incident cardiovascular events in men in a population-based cohort. Arterioscler Thromb Vasc Biol. 2014;34:2457-2464. doi:10.1161/ATVBAHA.114.303718 
21. Wang Y, Lam KS, Kraegen EW, et al. Lipocalin-2 is an inflammatory marker closely associated with obesity, insulin resistance, and hyperglycemia in humans. Clin Chem. 2007;53:34-41. doi:10.1373/ clinchem.2006.075614

22. Lee M-W, Lee M, Oh K-J. Adipose tissue-derived signatures for obesity and type 2 diabetes: adipokines, batokines and microRNAs. $J$ Clin Med. 2019;8:854. doi:10.3390/jcm8060854

23. Kocot J, Dziemidok P, Kiełczykowska M, Hordyjewska A, Szcześniak G, Musik I. Adipokine profile in patients with type 2 diabetes depends on degree of obesity. Med Sci Monit. 2017;23:4995-5004. doi:10.12659/MSM.904318

24. Adiyaman SC, Ozer M, Saydam BO, Akinci B. The role of adiponectin in maintaining metabolic homeostasis. Curr Diabetes Rev 2020;16(2):95-103. doi:10.2174/1573399815666190702155733

25. Yanai H, Yoshida H. Beneficial effects of adiponectin on glucose and lipid metabolism and atherosclerotic progression: mechanisms and perspectives. Int J Med Sci. 2019;20:1190.

26. Ohashi K, Ouchi N, Matsuzawa Y. Anti-inflammatory and anti-atherogenic properties of adiponectin. Biochimie. 2012;94:2137-2142. doi:10.1016/j.biochi.2012.06.008

27. Yamamoto S, Matsushita Y, Nakagawa T, Hayashi T, Noda M, Mizoue T. Circulating adiponectin levels and risk of type 2 diabetes in the Japanese. Nutr Diabetes. 2014;4:E130. doi:10.1038/ nutd.2014.27

28. Neville CE, Patterson CC, Linden GJ, et al. The relationship between adipokines and the onset of type 2 diabetes in middle-aged men: the PRIME study. Diabetes Res Clin Pract. 2016;120:24-30. doi:10.1016/j.diabres.2016.07.010

29. Bahceci M, Gokalp D, Bahceci S, Tuzcu A, Atmaca S, Arikan S. The correlation between adiposity and adiponectin, tumor necrosis factor alpha, interleukin-6 and high-sensitivity C-reactive protein levels. Is adipocyte size associated with inflammation in adults? J Endocrinol Invest. 2007;30:210-214. doi:10.1007/BF03347427

30. Al-Hamodi Z, AL-Habori M, Al-Meeri A, Saif-Ali R. Association of adipokines, leptin/adiponectin ratio and C-reactive protein with obesity and type 2 diabetes mellitus. Diabetol Metab Syndr. 2014;6:99. doi:10.1186/1758-5996-6-99

31. Huang Y, Yang Z, Ye Z, et al. Lipocalin-2, glucose metabolism and chronic low-grade systemic inflammation in Chinese people. Cardiovasc Diabetol. 2012;11:11. doi:10.1186/1475-2840-11-11

32. De la Chesnaye E, Manuel-Apolinar L, Zarate A, et al. Lipocalin-2 plasmatic levels are reduced in patients with long-term type 2 diabetes mellitus. Int J Clin Exp Med. 2015;8(2):2853-2859.

33. Rashad NM, El-Shal AS, Etewa RL, Wadea FM. Lipocalin-2 expression and serum levels as early predictors of type 2 diabetes mellitus in obese women. IUBMB Life. 2017;69:88-97. doi:10.1002/iub.1594

34. Putz DM, Goldner WS, Bar RS, Haynes WG, Sivitz WI. Adiponectin and C-reactive protein in obesity, type 2 diabetes, and monodrug therapy. Metabolism. 2004;53(11):1454-1461. doi:10.1016/j. metabol.2004.06.013

35. Yuan G, Zhou L, Tang J, et al. Serum CRP levels are equally elevated in newly diagnosed type 2 diabetes and impaired glucose tolerance and related to adiponectin levels and insulin sensitivity. Diabetes Res Clin Pract. 2006;72(3):244-250. doi:10.1016/j.diabres.2005.10.025

36. Ma L, Xu Y, Zhang Y, Ji T, Li Y. Lower levels of circulating adiponectin in elderly patients with metabolic inflammatory syndrome: a cross-sectional study. Diabetes Metab Syndr Obes. 2020;13:591-596. doi:10.2147/DMSO.S242397

37. Auguet T, Quintero Y, Terra X, et al. Upregulation of lipocalin-2 in adipose tissues of severely obese women: positive relationship with proinflammatory cytokines. Obesity. 2011;19:2295-2300. doi:10.1038/oby.2011.61

38. Wang W, Ye S, Qian L, et al. Elevated serum lipocalin-2 levels are associated with indexes of both glucose and bone metabolism in type 2 diabetes mellitus. Endokrynol Pol. 2018;69(3):276-282. doi:10.5603/EP.a2018.0030
39. Alkharfy KM, Al-Daghri NM, Vanhoutte PM, Krishnaswamy S, $\mathrm{Xu}$ A. Serum retinol-binding protein 4 as a marker for cardiovascular disease in women. PLoS One. 2012;7:e48612. doi:10.1371/journal. pone.0048612

40. Zatterale F, Longo M, Naderi J, et al. Chronic adipose tissue inflammation linking obesity to insulin resistance and type 2 diabetes. Front Physiol. 2020;10:Article No. 1607. doi:10.3389/fphys.2019.01607

41. Jin D, Guo H, Bu SY, et al. Lipocalin-2 is a selective modulator of peroxisome proliferator-activated receptor- $\gamma$ activation and function in lipid homeostasis and energy expenditure. FASEB J. 2011;25 (2):754-764. doi:10.1096/fj.10-165175

42. Zhang J, Wu Y, Zhang Y, LeRoith D, Bernlohr DA, Chen X. The role of lipocalin-2 in the regulation of inflammation in adipocytes and macrophages. Mol Endocrinol. 2008;22(6):1416-1426. doi:10.1210/ me.2007-0420

43. Guo H, Jin D, Zhang Y, et al. Lipocalin-2 deficiency impairs thermogenesis and potentiates diet-induced insulin resistance in mice. Diabetes. 2010;59(6):1376-1385. doi:10.2337/db09-1735

44. Paton CM, Rogowski MP, Kozimor AL, Stevenson JL, Chang H, Cooper JA. Lipocalin-2 increases fat oxidation in vitro and is correlated with energy expenditure in normal weight but not obese women. Obesity. 2013;21:E640-648. doi:10.1002/oby.20507

45. Xu Y, Ma X, Pan X, He X, Xiao Y, Bao Y. Correlations between serum concentration of three bone-derived factors and obesity and visceral fat accumulation in a cohort of middle aged men and women. Cardiovasc Diabetol. 2018;17:143. doi:10.1186/s12933-018-0786-9

46. Donath MY, Storling J, Berchtold LA, Billestrup N, MandrupPoulsen T. Cytokines and beta-cell biology: from concept to clinical translation. Endocrine Rev. 2008;29(3):334-350. doi:10.1210/ er.2007-0033

47. Li D, Yan Sun W, Fu B, Xu A, Wang Y. Lipocalin-2: the myth of its expression and function. Basic Clin Pharmacol Toxicol. 2020;127:142-151. doi:10.1111/bcpt.13332

48. Hu Y, Xue J, Yang Y, et al. Lipocalin-2 upregulation protects hepatocytes from IL1- $\beta$-induced stress. Cell Physiol Biochem. 2015;36 (2):753-762. doi:10.1159/000430135

49. Hansen D, Dendale P, Beelen M, et al. Plasma adipokine and inflammatory marker concentrations are altered in obese, as opposed to non-obese, type 2 diabetes patients. Eur $J$ Appl Physiol. 2010;109:397-404. doi:10.1007/s00421-010-1362-5

50. Neuparth MJ, Proença JB, Santos-Silva A, Coimbra S. Adipokines, oxidized low-density lipoprotein, and C-reactive protein levels in lean, overweight, and obese Portuguese patients with type 2 diabetes. Obesity. 2013;2013:Article ID 142097.

51. Raghushaker CR, Shashank T, Manista A. Evaluation of serum biomarkers [Leptin, Adiponectin, CRP, Oxidised-LDL] and lipid parameter in obese with type-2 diabetes mellitus: risk to CVD. J Adv Res Biol Sci. 2013;5(3):250-253.

52. Liu W, Zhou X, Li Y, et al. Serum leptin, resistin, and adiponectin levels in obese and non-obese patients with newly diagnosed type 2 diabetes mellitus: a population based study. Medicine. 2020;99(6): e19052. doi:10.1097/MD.0000000000019052

53. Coimbra S, Brandão Proença J, Santos-Silva A, Neuparth MJ. Adiponectin, leptin, and chemerin in elderly patients with type 2 diabetes mellitus: a close linkage with obesity and length of the disease. Biomed Res Int. 2014;2014:Article no, 701915. doi:10.1155/2014/701915

54. Rajković N, Zamaklar M, Lalic K, et al. Relationship between obesity, adipocytokines and inflammatory markers in type 2 diabetes: relevance for cardiovascular risk prevention. Int J Environ Res Public Health. 2014;11(4):4049-4065. doi:10.3390/ijerph110404049

55. Jung C-H, Kim B-Y, Mok J-O, Kang S-K, Kim C-H. Association between serum adipocytokine levels and microangiopathies in patients with type 2 diabetes mellitus. $J$ Diabetes Investig. 2014;5:333-339. doi:10.1111/jdi.12144 
56. Li X, Zhao Y, Jin Y, et al. Associations between serum adipocytokines and glycemic tolerance biomarkers in a rural Chinese population. PLoS One. 2017;12(8):e0182273. doi:10.1371/journal. pone. 0182273

57. Tong HV, Luu NK, Son HA, et al. Adiponectin and pro-inflammatory cytokines are modulated in Vietnamese patients with type 2 diabetes mellitus. J Diabetes Invest. 2017;8:295-305. doi:10.1111/jdi.12579

58. Liu C, Feng X, Li Q, Wang Y, Li Q, Hua M. Adiponectin, TNF- $\alpha$ and inflammatory cytokines and risk of type 2 diabetes: a systematic review and meta-analysis. Cytokine. 2016;86:100-109. doi:10.1016/ j.cyto.2016.06.028

59. Lee JM, Kim SR, Yoo SJ, Hong OK, Son HS, Chang SA. The relationship between adipokines, metabolic parameters and insulin resistance in patients with metabolic syndrome and type 2 diabetes. $J$ Int Med Res. 2009;37:1803-1812. doi:10.1177/147323000903700616

60. Han SJ, Boyko EJ, Fujimoto WY, Kahn SE, Leonetti DL. Low plasma adiponectin concentrations predict increases in visceral adiposity and insulin resistance. $J$ Clin Endocrinol Metab. 2017;102:4626-4633. doi:10.1210/jc.2017-01703

61. Gariballa S, Alkaabi J, Yasin J, Al Essa A. Total adiponectin in overweight and obese subjects and its response to visceral fat loss. BMC Endocr Disord. 2019;19:55. doi:10.1186/s12902-019-0386-z

62. Kadowaki T, Yamauchi T, Kubota N, Hara K, Ueki K, Tobe K. Adiponectin and adiponectin receptors in insulin resistance, diabetes, and the metabolic syndrome. J Clin Invest. 2006;116:1784-1792. doi:10.1172/JCI29126

63. Ferris WF, Naran NH, Crowther NJ, Rheeder P, van der Merwe L, Chetty N. The relationship between insulin sensitivity and serum adiponectin levels in three population groups. Horm Metab Res. 2005;37(11):695-701. doi:10.1055/s-2005-870580

64. Lopez-Jaramillo P. The role of adiponectin in cardiometabolic diseases: effects of nutritional interventions. J Nutr. 2016;146(2):422S426S. doi:10.3945/jn.114.202432

65. Petrone A, Zavarella S, Caiazzo A, et al. The promoter region of the adiponectin gene is a determinant in modulating insulin sensitivity in childhood obesity. Obesity. 2006;14(9):1498-1504. doi:10.1038/ oby. 2006.172

66. Mohlig M, Wegewitz U, Osterhoff M, et al. Insulin decreases human adiponectin plasma levels. Horm Metab Res. 2002;34:655-658. doi:10.1055/s-2002-38248

67. Lihn IS, Pedersen SB, Richelsen B. Adiponectin: action, regulation and association to insulin sensitivity. Obesity Rev. 2005;6(1):13-21. doi:10.1111/j.1467-789X.2005.00159.x

68. Mirea AM, Tack CJ, Chavakis T, Joosten LAB, Toonen EJM. IL-1 Family cytokine pathways underlying NAFLD: towards new treatment strategies. Trends Mol Med. 2018;24:458-471. doi:10.1016/j. molmed.2018.03.005
69. Zhao G, Dharmadhikari G, Maedler K, Meyer-Hermann M. Possible role of interleukin- $1 \beta$ in type 2 diabetes onset and implications for anti-inflammatory therapy strategies. PLoS Comput Biol. 2014;10(8): e1003798. doi:10.1371/journal.pcbi.1003798

70. Ma L, Su H, Wang Y, et al. Interleukin-1 $\beta$ (IL-1 $\beta$ ) C-511T polymorphism is associated with susceptibility to coronary artery disease in type 2 diabetic patients. Eur $J$ Inflamm. 2020;18:1-12. doi: $10.1177 / 2058739220918047$

71. Juge-Aubry CE, Somm E, Chicheportiche R, et al. Regulatory effects of interleukin (IL)-1, interferon- $\beta$, and IL-4 on the production of IL-1 receptor antagonist by human adipose tissue. J Clin Endocrinol Metab. 2004;89:2652-2658. doi:10.1210/jc.2003-031219

72. Tack CJ, Stienstra R, Joosten LA, Netea MG. Inflammation links excess fat to insulin resistance: the role of the interleukin-1 family. Immunol Rev. 2012;249(1):239-252. doi:10.1111/j.1600-065X.2012 $.01145 . \mathrm{x}$

73. Bing C. Is interleukin- $1 \beta$ a culprit in macrophage-adipocyte crosstalk in obesity? Adipocyte. 2015;4(2):149-152. doi:10.4161/21623945. 2014.979661

74. Boni-Schnetzler M, Thorne J, Parnaud G, et al. Increased interleukin (IL)-1beta messenger ribonucleic acid expression in beta-cells of individuals with type 2 diabetes and regulation of IL-1beta in human islets by glucose and auto-stimulation. J Clin Endocrinol Metab. 2008;93(10):4065-4074. doi:10.1210/jc.2008-0396

75. Morteza A, Nakhjavani M, Ghadiri-Anari A, Esteghamati A, Khalilzadeh O. Serum interleukin-1 and interleukin-6 are correlated neither with oxidized low density lipoprotein, nor with low-grade inflammation in patients with type 2 diabetes. Eur Cytokine Netw. 2011;22:107-112. doi:10.1684/ecn.2011.0282

76. Joung KH, Kim JM, Choung S, Lee JH, Kim HJ, Ku BJ. Association between IL-1beta and cardiovascular disease risk in patients with newly diagnosed, drug-naïve type 2 diabetes mellitus: a crosssectional study. Ann Transl Med. 2020;8(5):225. doi:10.21037/ atm.2020.01.17

77. Lee H-M, Kim -J-J, Kim H-J, Shong M, Ku BJ, Jo E-K. Upregulated NLRP3 inflammasome activation in patients with type 2 diabetes. Diabetes. 2013;62:194-204. doi:10.2337/db12-0420

78. Bastard JP, Maachi M, Lagathu C, et al. Recent advances in the relationship between obesity, inflammation, and insulin resistance. Eur Cytokine Netw. 2006;17:4-12.

\section{Publish your work in this journal}

Diabetes, Metabolic Syndrome and Obesity: Targets and Therapy is an international, peer-reviewed open-access journal committed to the rapid publication of the latest laboratory and clinical findings in the fields of diabetes, metabolic syndrome and obesity research. Original research, review, case reports, hypothesis formation, expert opinion and commentaries are all considered for publication. The manuscript management system is completely online and includes a very quick and fair peer-review system, which is all easy to use. Visit http://www.dovepress.com/testimonials.php to read real quotes from published authors. 